\title{
Correction to: Factors associated with poorer outcomes in the surgical treatment of multiligament knee injuries
}

\author{
Eduard Alentorn-Geli ${ }^{1,2,3,4}$. Alexander L. Lazarides ${ }^{1}$. Gangadhar M. Utturkar ${ }^{1,5}$. Heather S. Myers ${ }^{6}$. \\ Kristian Samuelsson ${ }^{7,8}$. J. H. James Choi ${ }^{1}$. Joseph J. Stuart ${ }^{1}$. Claude T. Moorman III ${ }^{1,9}$
}

Published online: 19 September 2018

(c) European Society of Sports Traumatology, Knee Surgery, Arthroscopy (ESSKA) 2018

\section{Correction to: \\ Knee Surgery, Sports Traumatology, Arthroscopy \\ https://doi.org/10.1007/s00167-018-5053-9}

The author would like to correct the following errors in the publication of the original article:

The title of the article should read as "Factors associated with poorer outcomes in the surgical treatment of multiligament knee injuries".

In the introduction section, in the first paragraph, the seventh line should read as "In the short term, these injuries can lead to.

Instability, poor function, and inability to reach pre-injury activity level [13, 14, 16, 45, 46, 52]".

The original article can be found online at https://doi.org/10.1007/ s00167-018-5053-9.

Claude T. Moorman III

T.Moorman@orthocarolina.com

1 Department of Orthopaedic Surgery, Duke Sports Sciences Institute, Duke University, Durham, NC, USA

2 Fundación García-Cugat, Barcelona, Spain

3 Artroscopia GC, S.L., Barcelona, Spain

4 Mutualidad Catalana de Futbolistas, Federación Española de Fútbol, Barcelona, Spain

5 Department of Biomedical Engineering, Duke University, Durham, NC, USA

6 Department of Physical Therapy, Duke University, Durham, NC, USA

7 Department of Orthopaedics, Sahlgrenska University Hospital, Mölndal, Sweden

8 Department of Orthopaedics, Institute of Clinical Sciences, The Sahlgrenska Academy, University of Gothenburg, Gothenburg, Sweden

9 Deparment of Orthopaedic Surgery, OrthoCarolina, Atrium Health, 1915 Randolph Road, Charlotte, NC 28207, USA
In the introduction section, in the second paragraph, the third line should read as "There has been a recent interest in the investigation of predictability of patient- reported and functional outcomes in MLKI or knee dislocations [2, 27, 37].

In the Materials and methods section, the first line should be "This investigation was performed at the Department of Orthopaedic Surgery at Duke University."

In the Discussion section, in the sixth paragraph, second line should read as "First, the sample size may be limited for research with subgroup comparisons and is insufficient for a multivariate analysis".

The Compliance with Ethical standards should read as

Conflict of interest The authors declare that there are no conflicts of interest for the present study.

Funding No funding was received for the present study.

Ethical approval This study has been conducted in accordance with the ethical standards at our Institution and with the 1964 Helsinki Declaration and its later amendments. 